Revue d'histoire de l'Amérique française

REVUE D.HISTOIRE DE L'AMÉRIQUE FRANÇAISE

\title{
Les engagés pour le Canada partis de Nantes (1725-1732)
}

\section{Gabriel Debien}

Volume 33, numéro 4, mars 1980

URI : https://id.erudit.org/iderudit/303814ar

DOI : https://doi.org/10.7202/303814ar

Aller au sommaire du numéro

Éditeur(s)

Institut d'histoire de l'Amérique française

ISSN

0035-2357 (imprimé)

1492-1383 (numérique)

Découvrir la revue

Citer cette note

Debien, G. (1980). Les engagés pour le Canada partis de Nantes (1725-1732).

Revue d'histoire de l'Amérique française, 33(4), 583-586.

https://doi.org/10.7202/303814ar d'utilisation que vous pouvez consulter en ligne.

https://apropos.erudit.org/fr/usagers/politique-dutilisation/ 
NOTE DE RECHERCHE

\section{- II - \\ LES ENGAGÉS POUR LE CANADA \\ PARTIS DE NANTES * \\ (1725-1732)}

GABRIEL DEBIEN
Charenton, France

Aux XVIIe et XVIIIe siècles, les départs pour le Canada ne paraissent avoir été nombreux que par La Rochelle et les ports normands. Les contrats d'engagement n'ont pas encore été méthodiquement recherchés dans les minutiers de Honfleur, de Rouen et du Havre. Le dépouillement des minutiers nantais de 1632 à 1732 a fait connaître 6000 engagés mais, sauf une vingtaine pour le Canada, tous pour les îles. Les départs pour le Canada datent des années qui vont de 1725 à 1732 . À cette époque, on fortifiait Louisbourg. Il s'agit donc surtout d'ouvriers professionnels, mais qui ne paraissent pas recrutés, sauf peut-être les quatre menuisiers, pour les travaux de fortification. Il y a là 2 boulangers, 2 tanneurs, un boucher, un cardeur de laine, un tailleur, un boutonnier, un cordonnier, un chirurgien, un potier d'étain, mais aucun paysan.

Deux viennent de Paris, un de Nantes, un de La Rochelle, tous les autres de la campagne, dont 6 de la région nantaise, deux du Maine, deux de Poitou, un du diocèse de Blois, un du diocèse de Rennes, un d'Hennebont près de Lorient, un dernier des environs de Paris.

* Pour compléter cette documentation voir: Gabriel Debien, “Les engagés pour le Canada du XVIIe siècle, vus de La Rochelle”, RHAF, 6,2 (sept. 1952): 177-223; 6,3 (déc. 1952): 374-407, 456; 6,4 (mars 1953): 536-559; 7,1 (juin 1953): 88-109; 7,2 (sept. 1953): 259-286; 8,4 (mars 1955): 496-517; 9,1 (juin 1955): 55-73; 9,2 (sept. 1955): 250-271. "Les engagés pour le Canada au XVIIIe siècle", RHAF, 13,2 (sept. 1959): 247-261; 13,3 (déc. 1959): 402-421; 13,4 (mars 1960): 550-561; 14,1 (juin 1960): 87-108; 14,2 (sept. 1960): 246-258; 14,3 (déc. 1960): 430-440; 14,4 (mars 1961): 583-602. 


\section{9 mars 1725}

- au sieur Guillaume De Hort, habitant de Louisbourg en l'île Royale s'engagent pour trois ans et passeront sur l'Espérance, de La Rochelle, capitaine George Godefret (Buisson, notaire).

1 - François Bertrand, 23 ans, tanneur, de Saint-Grade ${ }^{1}$ en l'évêché de Rennes, fils de Pierre. Il signe. Il recevra 50 livres par an.

2 - Henri Poitevin, 22 ans, fils de Gilles, de la paroisse de SaintGilles ${ }^{2}$, évêché de Luçon, signe, à 40 livres.

3 - Charles Salis, 23 ans, fils de Guillaume, de Guérande³, 40 livres.

4 - Jen Brazebeu, 20 ans, fils d'Yves, du Croisic ${ }^{4}, 40$ livres.

\section{7 février 1727}

- à M. Genet, entrepreneur des ouvrages du roi à Louisbourg, qui agit à Nantes par noble homme Louis Fosseaux, négociant.

5 - Jacques Branche, 20 ans, d'Onzain ${ }^{5}$, évêché de Blois, fils de Jacques.

6 - Louis Logier, 25 ans, de Nantes, fils de Louis, signe.

7 - Pierre Langlois, 29 ans, de Sussé6, évêché de Nantes, fils de Guillaume.

8 - Jean Perrot, 26 ans, fils d'Yves, de Frégréac ${ }^{7}$, évêché de Nantes. Signe.

s'engagent pour deux ans. Ils travailleront de leur métier de menuisier, seront traités en artisans; leur aller et retour sont payés et ils recevront 300 livres par an, sauf Branche qui n'aura que 200 livres (Boufflet, notaire).

\section{2 février 1729}

- à dame veuve Nicolas Berchou, habitante de l'île Royale du cap Breton à Louisbourg, propriétaire de la Marie-Charlotte de 30 tonneaux, capitaine le sieur Charles Leroy, qui agit pour elle, s'engagent:

1 Non identifié.

2 Chef-lieu de canton de l'arrondissement des Sables d'Olonne (Vendée).

3 Chef-lieu de canton de l'arrondissement de Saint-Nazaire (Loire-Atlantique).

4 Ibid.

5 Commune du canton d'Herbault, arrondissement de Blois (Loir-et-Cher).

6 Sucé, commune du canton de la Chappelle-sur-Erdre, arrondissement de Nantes (Loire-Atlantique).

7 Canton de Saint-Nicolas de Redon, arrondissement de Saint-Nazaire (L.-A.). 
9 - Henri-Maurice Dugué, potier d'étain, de la paroisse SaintNicolas de Paris, fils de Maurice, 36 livres par an.

10 - Pierre Barbier, dit Forac, 16 ans, boutonnier, de Liré, évêché de Nantes ${ }^{8}$, fils de François et d'Anne-Marie Lesut, 31 livres par an. Signe.

11 - Silvain Lefebvre, 22 ans, cardeur et fileur de laine, fils de Silvain, de Vernay-le-Chétif, évêché du Mans", 36 livres.

travailleront 3 ans de leur métier, "ou autres". Reçoivent un an d'avance (Buisson, notaire).

\section{1er juillet 1729}

- à René Penne, sur la Minerve, capitaine Pétrimoulx, pour Québec.

12 - Charles Leroy, 30 ans, boucher, de la paroisse Notre-Dame de La Rochelle. Ne sait signer. Pas de gages précis.

13 - Jean Latouche, 18 ans, chirurgien, de Pouillé10 en Poitou (Uriens, notaire). Pas de gages précis.

\section{6 juillet 1731}

- au sieur de la Villetreux, armateur de la Victoire, capitaine Jacques de La Chapelle:

14 - Jean Boliegre, 20 ans, garçon boulanger, de Gournay ${ }^{11}$ près Paris, ne sait signer (Uriens, notaire).

\section{3 janvier 1732}

- à Nicolas Perré, armateur de la Miverne, pour Québec:

15 - Toussaint Baudy, 18 ans, cordonnier, de Saint-Étienne de Clisson ${ }^{12}$, fils de René.

16 - Julien Le Menetec, 19 ans, tailleur, d'Hennebont ${ }^{13}$, fils de Jean, signe (Uriens, notaire).

8 Commune du canton de Champtoceaux, arrondissement de Cholet (Maine-et-

9 Verneil-le-Chétif, village du canton de Mayet, arrondissement de La Flèche.

10 Commune du canton de Saint-Julien l'Ars, arrondissement de Poitiers (Vienne).

Denis).

Gournay-sur-Marne, commune de l'arrondissement du Raincy (Seine-Saint-

12 Chef-lieu de canton de l'arrondissement de Nantes (Loire-Atlantique).

13 Chef-lieu de canton de l'arrondissement de Lorient (Morbihan). 


\section{0 juin 1732}

- à Boucault, négociant à Québec pour René Prat, maîtretanneur, 200 livres par an.

17 - Julien Courvisier, 32 ans, garçon tanneur, fils de Guillaume, de Saint-Mars la Brière ${ }^{14}$ (Uriens, notaire).

18 - Jacques-François Goussard, 24 ans, de Saint-Nicolas de Paris, fils de Pierre, ne sait signer (Uriens, notaire).

14 Commune de canton de Montfort-le-Rotrou, arrondissement du Mans (Sarthe). 